\title{
THE ASSESSMENT OF PRIORITIES IN THE CONSTRUCTION OF NEW HIGH-SPEED RAILWAY LINES IN CZECH REPUBLIC BY USING THE STEM METHOD
}

\author{
Pavel Purkart*, Jan KruntoráD, LukÁŠ TÝFA \\ Czech Technical University in Prague, Faculty of Transportation Sciences, Department of Transportation \\ Systems, Horská 3, 12803 Prague 2, Czech Republic \\ * corresponding author: purkapav@fd.cvut.cz
}

\begin{abstract}
The aim of the paper is to set priority of The Fast Connection sections ("Rychlá spojení" in Czech, abbreviation "RS") building mentioned above by using the STEM method. The method is used to select projects with the maximum benefit if the budget is limited. There has not been set a limit for individual RS sections as a limitation of financial costs. The decisive factor is the order in which individual RS sections should be built on the basis of evaluation criteria.
\end{abstract}

Keywords: High-speed Railway Lines (HSL), The Fast Connections (RS), Czech Republic, mathematic model, the STEM method, project choice, evaluation criteria.

\section{InTRODUCTION AND GOALS}

Today a great effort is being made in the Czech Republic to prepare the HSL network in relation to the previously developed RS concept. Now, the Czech railway network does not have any line in HSL parameters, which is not acceptable in the long term - with regard to sustainable development of the territory, taking into account the situation not only in the neighbouring Western European states, but also global development [1].

The main directions of the fast railway network have been defined [2]:

- RS1 Praha (Prague) - Brno - Ostrava - [Poland],

- RS2 Brno - [Slovakia/Austria],

- RS3 Praha - Plzeň (Pilsen) - [Germany] (western direction - München),

- RS4 Praha - [Germany] (northern direction - Dresden) with possible branch (Most - Chomutov, Žatec, Louny),

- RS5 Praha - Hradec Králové/Liberec - [Poland].

The implementation of the RS1, RS2 and RS4 sections is monitored as a priority. In these cases, the Správa železnic (the main infrastructure manager of Czech railway network) is already carrying out project preparation. The aim of this article is thus to open up the controversy as to whether the above-mentioned sections in terms of benefits should be actually built first, respectively whether there is a more appropriate order of implementation.

The current design state is schematically shown in Figure 1

\section{Understanding And Solving The ISSUE}

The main aim of the paper is to set priorities in the construction of high-speed railway lines in the Czech Republic using the STEM method (Step Method).

The use of the STEM method is defined in the following chapter. The method is used for project selection due to limited funding opportunities while maximizing the benefits of their implementation. In this case, the method was slightly modified (the method mandatory used for economic problems was modified for a purpose for maximization benefits within economic costs at first).

\section{Solution of the Issue}

\subsection{Method STEM}

The STEM method can solve linear mathematical problems with more purpose functions. The aim of this method is to find compromise solutions, whose realizations should bring most benefits. The main principle of the method is the calculation of purpose function ideal values for individual cases. This calculation is followed by minimizing compromise solution deviation from ideal purpose function values. The basic of the method is an interactive procedure of searching the compromise solution.

Benefit of the STEM method is, that there is only minimal need of communication between a submitter and a solver (comparing to another methods). The scale method for individual criterions is set by calculation. The submitter must decide whether the result of the calculation is acceptable for him or not. So, the method consists of calculation and decision-making process. The calculation is stopped, if submitter finds the result acceptable, otherwise the solver must be informed by submitter in order to change the criteri- 


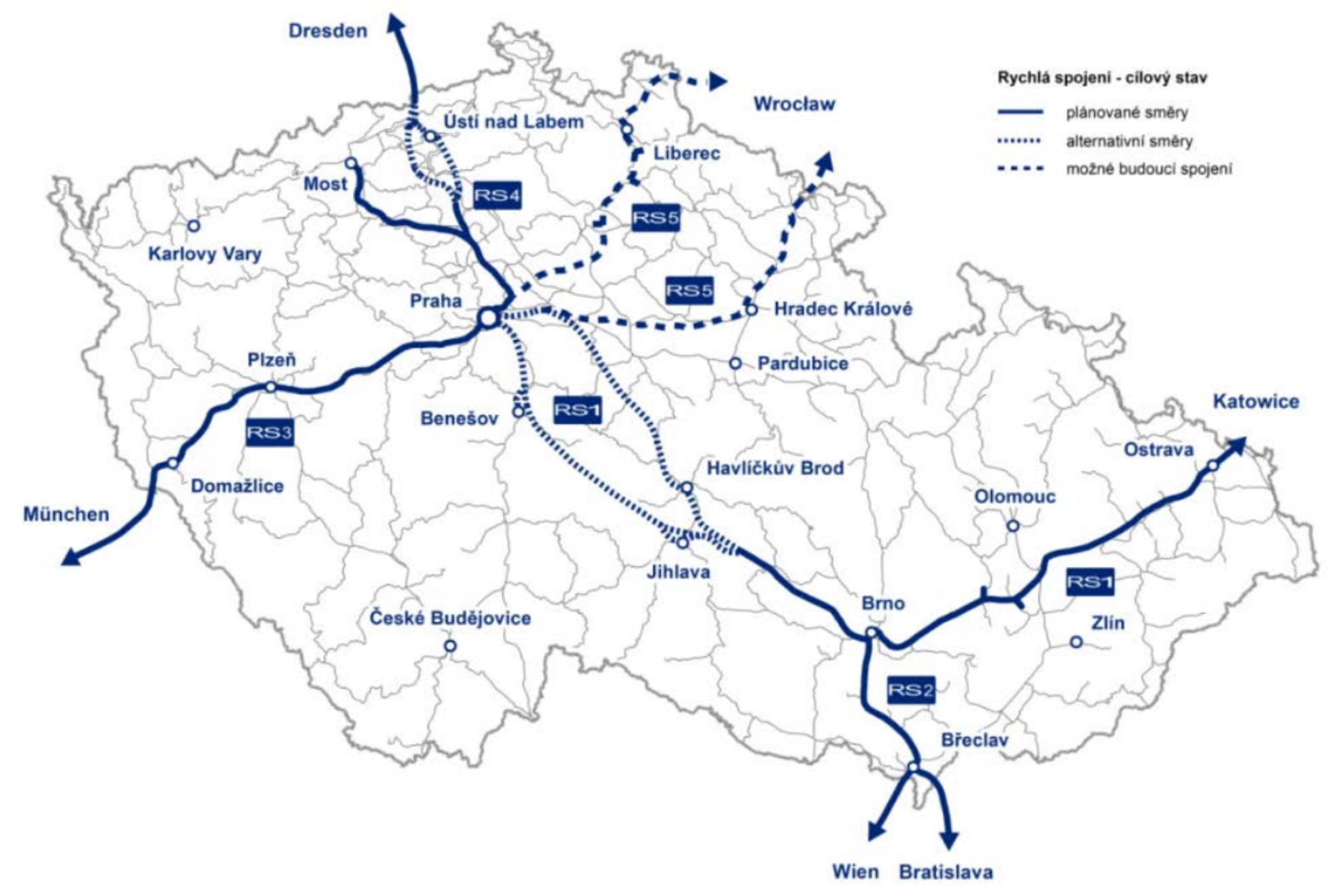

Figure 1. Suggestion of RS, source: Správa železnic [3].

ons or their numbers, the whole calculation is made again 3 .

The STEM method consists of following steps:

(1.) Solver calculates optimal solution for individual criterions (purpose function) separately. The number of calculations fits the number of criterions.

(2.) Solver calculates the scales of individual criterions $\left(\chi ; X_{J}\right)$ according to the Formula (1):

$$
w_{i}=\frac{z_{i i}-\min _{i=j \ldots k} z_{i j}}{z_{i i}} \frac{\alpha}{\sqrt{\sum_{i=1}^{n} c_{i j}^{2}}}
$$

where: $z_{i j}$ - element of optimalization criterions values matrix for optimalization in individual optimalization criterion $\left(z_{i j}\right.$ is the value of optimalization criterion $j=1, \ldots, k$ in case of optimalization according to the criterion $i=1, \ldots, k)$,

$c_{i j}$ - element of the price matrix - element of individual optimalization criterion coefficients matrix. Value $\alpha$ comes from the Equation (2):

$$
\sum_{i=1}^{k} \frac{z_{i i}-\min _{i=j \ldots k} z_{i j}}{z_{i i}} \frac{\alpha}{\sqrt{\sum_{i=1}^{n} c_{i j}^{2}}}=1
$$

In reality we have to calculate coefficient $\alpha$ value first and then count the scales of individual criterions. If the scale fits the constraint $w_{i}>0$ for more criterions, the solver adds new variable and solves the model with new optimalization criterion (3).

$$
\min f(x, d)=d
$$

There is a form for variable $d$ :

$$
d=\max _{i=j \ldots k}\left\{w_{i}\left(z_{i i}-\sum_{j \in J} c_{i j} X_{J}\right)\right\}
$$

We have to implement constraint (5) for correct calculation:

$$
w_{i i}\left(z_{i i}-\sum_{j \in J} c_{i j} X_{J}\right) \leq d
$$

If constraint $w_{i}>0$ fits for only one value $i=$ $1, \ldots, k$, solver cen simplify the constraint (5) to $(6)$ :

$$
\min f(x)=\sum_{i=1}^{k} w_{i i}\left(z_{i i}-\sum_{j \in J} c_{i j} X_{J}\right)
$$

(3.) Solver presents the results to the submitter. The submitter can modify the criterions or add/remove some of them, if he does not find the results acceptable - but we haven't to do that, if the first solution should be the best. Solver goes back to step 2 .

(4.) Solver has found compromise solution, if the submitter of satisfied with the result. The solution is optimal, if the value $d=0$ is reached. 


\subsection{Calculation According to the STEM Method AND RESUlt}

For the purposes of the calculation, a total of six logical RS sections were identified:

(1.) Praha - Brno,

(2.) Brno - Ostrava - [Poland],

(3.) Brno - [Slovakia/Austria $]$,

(4.) Praha - Plzeň - [Germany],

(5.) Praha - Ústí nad Labem - [Germany] (northern direction - Dresden) with branch,

(6.) Praha - Hradec Králové/Liberec - [Poland].

The following evaluation criteria were used to determine priorities in the construction of RS sections:

- average coefficient of reduced travel times in chosen connections: the research team (authors of the articles + colleagues from the department) determined RS sections, including international ones, for which the RS construction is crucial. For these sections there was calculated the number of shorter travel times compared to the current situation and in the case RS section is realized. Then these numbers were distributed on individual RS sections and the average for these sections were calculated,

- number of redirected long-distance lines expressed as an importance: three categories were set for each evaluated section based on the evaluation below:

1: up to 10 redirected long-distance routes in both directions per day,

2: up to 30 redirected long-distance routes in both directions per day,

3: over 30 redirected long-distance routes in both directions per day.

In this criterion there was monitored the possible placement on the RS network of the current longdistance lines, especially close to agglomerations (Prague, Brno, Ostrava), where the selected sections of the railway network are already overloaded,

- routing difficulty: the average was calculated based on the questioning an expert team of four experts. The issue of routing was considered broadly (not only regarding natural barriers, but also routing through urban areas, etc.) and the logic of values is divided into these categories:

1: very difficult routing,

1,5:difficult routing,

2: medium difficult routing,

2,5:routing without major problems,

3 : simple routing.

- road traffic redirection potential: for all $\mathrm{RS}$ sections, a section on the road network was determined, from which the decisive load value in vehicles/24 hours was taken. The source of data is National traffic census 2016. In all cases, the section on a parallel highway network with logical minimum value of traffic volumes was taken into account, so this criterion represents the minimal potential for traffic redirection from roads.

- agglomeration potential: the research team set agglomerations, including foreign ones, on which the built RS sections will have a direct influence. For all agglomerations the number of inhabitants was found and then their relation to individual RS sections was evaluated. For example, for Pilsen agglomeration the RS3 section is crucial, but the RS2 section has a minimal importance - this logic was used to evaluate all agglomerations regarding a number of inhabitants. The importance of an agglomeration for a given section was multiplied with its number of inhabitants and the final values were cumulated into individual sections.

All criteria have been compiled in such a way that as their value increases, their benefits are maximized.

The specific values of evaluation criteria are summarized in Table 1

The STEM method is a very interactive method because it calculates the weight criteria for every mathematical model. There were two mathematical models considered in the calculation (the first one to select two projects out of six and the second one to select four projects out of six), therefore weights were determined twice. These weights are shown in Table 2

In both models, the highest criteria weights were assigned to number of redirected long-distance lines expressed as an importance and routing difficulty, both above $30 \%$. The average coefficient of reduced travel times in chosen connections has a value oscillating around a weight of $20 \%$. On the other hand, in both calculations there were assigned very low values for road travel redirection potential and agglomeration potential, these weights are lower than $5 \%$.

The calculation was performed for both versions of the model, and in neither case $d=0$ was achieved. It shows that compromise solutions, not optimal ones, have been achieved.

The two top prioritized high-speed railway line sections have been set by the STEM method:

- Praha - Brno,

- Brno - [Slovakia/Austria].

These two sections have middle priority:

- Brno - Ostrava - [Poland],

- Praha - Plzeň - [Germany].

The rest of sections was described as a low building priority:

- Praha - Ústí nad Labem - [Germany with branch],

- Praha - Hradec Králové/Liberec - [Poland]. 


\begin{tabular}{|c|c|c|c|c|c|}
\hline $\begin{array}{l}\text { section of railway } \\
\text { line RS }\end{array}$ & $\begin{array}{l}\text { average } \\
\text { efficient } \\
\text { reduced } \\
\text { times in } \\
\text { connections } \\
\text { conen }\end{array}$ & $\begin{array}{l}\text { number of } \\
\text { redirected long- } \\
\text { distance lines } \\
\text { expressed as an } \\
\text { importance [-] }\end{array}$ & $\begin{array}{l}\text { routing dif- } \\
\text { ficulty [-] }\end{array}$ & $\begin{array}{l}\text { road traffic redi- } \\
\text { rection potential } \\
\text { [vehicles per day } \\
\text { in thousands in } \\
\text { chosen point of a } \\
\text { road network] }\end{array}$ & $\begin{array}{l}\text { agglomeration } \\
\text { potential [-] }\end{array}$ \\
\hline Praha - Brno & 2,13 & 3 & 1,6 & 39 & 22 \\
\hline Brno - Ostrava - PL & 1,85 & 2 & 2,5 & 22 & 15 \\
\hline Brno - SK/A & 1,85 & 2 & 3,0 & 23 & 21 \\
\hline Praha - Plzeň - D & 1,73 & 3 & 1,6 & 31 & 13 \\
\hline Praha - Ústí n. L. - D & 2,23 & 2 & 1,5 & 24 & 20 \\
\hline Praha - HK/Lbc - PL & 2,39 & 1 & 1,9 & 23 & 12 \\
\hline
\end{tabular}

TABle 1. Specific values of evaluation criteria, source: Authors.

\begin{tabular}{lll}
\hline criterion & $\begin{array}{l}\text { weight criterion for selecting } \\
\text { projects }\end{array}$ & $\begin{array}{l}\text { weight criterion for selecting } 2 \\
\text { projects }\end{array}$ \\
\hline $\begin{array}{l}\text { average coefficient of reduced } \\
\text { travel times in chosen connections }\end{array}$ & & 0.181 \\
[-] & \\
\hline $\begin{array}{l}\text { number of redirected long- } \\
\text { distances lines expressed as an }\end{array}$ & & 0.407 \\
importance [-] & & \\
\hline routing difficulty [-] & 0.361 & 0.372 \\
\hline $\begin{array}{l}\text { road traffic redirection potential } \\
\text { [vehicles per day in thousands in }\end{array}$ & 0.024 & 0.013 \\
chosen point of a road network] & & \\
\hline agglomeration potential [-] & 0.027 & 0.028 \\
\hline
\end{tabular}

TABLE 2. Weight criteria set by STEM method for cases of selecting 2 and 4 projects, source: Authors.

\section{Conclusion}

It is obvious from the calculation, according to evaluation criteria, that the top priorities of construction have sections Praha - Brno and Brno - [Slovakia/Austria]. While the plans of Správa železnic (the main infrastructure manager of Czech railway network) counts with the section Praha - Ústí nad Labem - [Germany], result of this paper prefers a construction of the section Praha - Plzeň - [Germany]. It is also possible to assume that in the section Prague - Ústí nad Labem - [Germany], the railway already uses its potential to a considerable extent, so its construction was not identified as a priority by the model.

It is evident that the significant influence on the calculation according to the STEM method had the number of long-distance transport lines transferred, which in the case of the route through Plzeñ is relatively significant (lines Ex6, R16 and R26). This factor apparently helped significantly to increase the priority of construction of the RS through Plzeň than through Ústí nad Labem.

\section{ACKNOWLEDGEMENTS}

All the facts presented in the article are based on the results of research on CTU Faculty of Transportation Sciences, Department of Transport Systems. This work was supported by the Grant Agency of the Czech Technical University in Prague, grant No. SGS18/150/OHK2/2T/16
Railway track parameters for transportation service optimization and No. SGS20/138/OHK2/2T/16 Design and optimal use of railway infrastructure parameters.

\section{REFERENCES}

[1] P. Purkart. Optimal cooperation of public transport segments. Praha: Defense date 2019-12-06. Doctoral Minimum. CTU FTS. Department of Transportation Systems. Supervised by Týfa, L.

[2] High-speed rails in the Czech Republic. [online], Praha: Správa železnic, 2020 [cit. 2020-02-22]. Available from: https://www.szdc.cz/vrt/

[3] D. Teichmann, M. Dorda. Comparison of Two Selected Methods in Evaluating of Investments in Transport Infrastructure. In: Finance and Performance of Firms in Science, Education and Practice : proceedings of the 7th International Scientific Conference : April 23-24, 2015, Zlín, Czech Republic. Zlín: Tomas Bata University in Zlín, 2015. pp. 1524-1536. ISBN 978-80-7454-482-8. 